\title{
Application of functional data analysis to classify communities according to the pattern of malaria incidence, to guide targeted control strategies.
}

Sokhna DIENG ( $\square$ sokhna.dieng@etu.univ-amu.fr )

Aix Marseille Univ, IRD, INSERM, SESSTIM, Marseille, France https://orcid.org/0000-0003-0603-1986

Pierre Michel

Aix Marseille Univ, CNRS, EHESS, Centrale Marseille, AMSE, Marseille, France

Abdoulaye Guindo

Aix Marseille Univ, IRD, INSERM, SESSTIM, Marseille, France

Kankoe Sallah

Aix Marseille Univ, IRD, INSERM, SESSTIM, Marseille, France

\section{El-hadj $\mathrm{Ba}$}

UMR VITROME, Campus International IRD-UCAD de I'IRD, Dakar, Senegal

\section{Badara Cissé}

Institut de Recherche en Santé, de Surveillance Epidemiologique et de formation (IRESSEF), Diamniadio,

\section{Senegal}

\section{Patrizia Carrieri}

Aix Marseille Univ, IRD, INSERM, SESSTIM, Marseille, France

\section{Cheikh Sokhna}

UMR Vitrome, Campus International IRD-UCAD de I'IRD, Dakar, Senegal

\section{Paul Milligan}

London School of Hygiene and Tropical medicine, London, United Kingdom

Jean Gaudart

Aix Marseille Univ, APHM, INSERM, IRD, SESSTIM, Hop Timone, BioSTIC, Biostatistic \& ICT, Marseille, France

\section{Research article}

Keywords: Functional data analysis, Time series clustering, Malaria patterns, Malaria dynamic, Hierarchical ascending clustering,

Posted Date: February 26th, 2020

DOI: https://doi.org/10.21203/rs.2.24479/v1 
License: (c) (i) This work is licensed under a Creative Commons Attribution 4.0 International License. Read Full License

Version of Record: A version of this preprint was published on June 11th, 2020. See the published version at https://doi.org/10.3390/ijerph17114168. 


\section{Application of functional data analysis to classify communities according to}

2 the pattern of malaria incidence, to guide targeted control strategies.

4 Sokhna Dieng*1, Pierre Michel $^{2}$, Abdoulaye Guindo ${ }^{1,3}$, Kankoe Sallah $^{1,4}$, El-hadj Ba ${ }^{5}$, Badara

5 Cissé $^{6}$, Patrizia Carrieri ${ }^{1}$, Cheikh Sokhna ${ }^{5}$, Paul Milligan ${ }^{7}$, Jean Gaudart ${ }^{8}$

$7 \quad{ }^{1}$ Aix Marseille Univ, IRD, INSERM, SESSTIM, Marseille, France.

$8 \quad{ }^{2}$ Aix Marseille Univ, CNRS, EHESS, Centrale Marseille, AMSE, Marseille, France

$9 \quad{ }^{3}$ Malaria Research and Training Center - Ogobara K Doumbo, FMOS-FAPH, Mali-NIAID-

10 ICER, Université des Sciences, des Techniques et des Technologies de Bamako, Bamako, Mali

$11 \quad{ }^{4}$ AP-HP, Hôpital Bichat, Unité de Recherche Clinique PNVS

$12{ }^{5}$ UMR VITROME, Campus International IRD-UCAD de l'IRD, Dakar, Senegal

$13{ }^{6}$ Institut de Recherche en Santé, de Surveillance Épidémiologique et de Formation (IRESSEF),

14 Diamniadio, Sénégal

$15 \quad{ }^{7}$ London school of hygiene and tropical medicine, London, United Kingdom

$16{ }^{8}$ Aix Marseille Univ, APHM, INSERM, IRD, SESSTIM, Hop Timone, BioSTIC, Biostatistic

$17 \&$ ICT, Marseille, France

18 * Corresponding author: sokhna.dieng@etu.univ-amu.fr 
Abstract

\section{Background}

24 Effective targeting of malaria control in low transmission areas requires identification of 25 transmission foci or hotspots. We investigated the use of functional data analysis to identify and describe spatio-temporal pattern of malaria incidence in an area with seasonal transmission in west-central Senegal.

\section{Method}

Malaria surveillance was maintained over 5 years from 2008 to 2012 at health facilities serving a population of 500,000 in 575 villages in two health districts in Senegal. Smooth functions were fitted from the time series of malaria incidence for each village, using cubic B-spline basis functions. The resulting smooth functions for each village were classified using hierarchical clustering (Ward's method), using several different dissimilarity measures. The optimal number of clusters was then determined based on four cluster validity indices, to determine the main types of distinct temporal pattern of malaria incidence. Epidemiological indicators characterizing the resulting malaria incidence pattern in terms of the timing of seasonal outbreaks, were calculated based on the slope (velocity) and rate of change of the slope (acceleration) of the incidence over time.

\section{Results}

Three distinct patterns of malaria incidence were identified. A pattern characterized by high

41 incidence, in 12/575 (2\%) villages, with average incidence of 114 cases/1000 person-years over the 5 year study period; a pattern with intermediate incidence in 97 villages (17\%), with average incidence of 13 cases/1000 person-years; and a pattern with low incidence in $466(81 \%)$

44 villages, with average incidence 2.6 cases/1000 person-years. Epidemiological indicators 
45 characterizing the fluctuations in malaria incidence showed that seasonal outbreaks started later,

46 and ended earlier, in the low incidence pattern.

\section{Conclusion}

48 Functional data analysis can be used to classify communities based on time series of malaria

49 incidence, and to identify high incidence communities. Indicators can be derived from the fitted

50 functions which characterize the timing of outbreaks. These tools may help to better target

51 control measures.

\section{Trial registration}

53 The data used in this work come from the clinical trial NCT 00712374. The trial is registered 54 at www.clinicaltrials.gov, number NCT 00712374.

55

56 Keywords: Functional data analysis; Time series clustering; Malaria patterns; Malaria 57 dynamic; Hierarchical ascending clustering;

58

60

61

62

63

64

65 


\section{Background}

67 In areas of low malaria transmission, because of the spatial heterogeneity of malaria incidence, WHO recommends the development of targeted control strategies adapted to the local epidemiological context [1] . Effective targeting requires identification of transmission foci or hotspots based on epidemiological and environmental data. In this paper we introduce an approach using functional data analysis to classify villages on the basis of the pattern of malaria incidence over a 5-year period, to inform the development of targeted control strategies in westcentral Senegal.

The principle of functional data analysis is that the observed data can be described by smooth functions which are estimated in order to understand the underlying patterns in the data. These functions can be obtained for each of a large number of units (communities), clustering algorithms can then be used to identify broad types of temporal pattern. For time series of disease incidence, the slope of the function, and the rate of change in the slope (the velocity and acceleration), are useful indicators which can be calculated to characterize key features of the data. A considerable amount of research have been dedicated to the development of statistical methods and tools for analysis of functional data [2-6]. The work by Ramsay et al. has made these approaches popular, and $\mathrm{R}$ and Matlab programs have made the methods available to a wider group of researchers [5]. Applications in public health and biomedical sciences are reviewed by Ullah and Finch (2013) [7]. The aim of this study was to investigate the use of these methods to understand spatio-temporal variation of malaria incidence, to inform targeting malaria control measures in a low transmission area of Senegal. Existing approaches used to target malaria risk areas are based on incidence rate, and prevalence [8-14] in discrete time periods [15-19]. In contrast, the functional data approach the whole time series to be characterized, potentially giving a better understanding of how intervention should be targeted. 


\section{Methods}

\section{Study area and dataset}

The data used for this study from 2008 to 2012 were collected during a field trial of Seasonal Malaria Chemoprevention in children in the west-central Senegal [20, 21]. Data for 575 villages in the rural health districts of Bambey and Fatick, have been used in this analysis. This area is a part of the two national health district where national malaria control estimated the incidence under 5 cases /1000 person-years in 2018 [22].

Malaria surveillance was maintained in 38 health facilities serving a population of about 500,000 living in 575 villages (single villages or groups of adjacent hamlets). Malaria cases were patients at health facilities with fever or history of fever, in the absence of evident alternative causes of the fever, who had a positive rapid diagnostic test (RDT). Date of diagnosis, village of residence, and other details were obtained for each case from facility registers. The surveillance system is described by Cisse et al (in the main paper and in supplement S3) [20]. The population was enumerated through a census in 2008 and updated through visits to each household at approximately 10 months intervals from 2008 to 2012 . Coordinates of the centre of each village were obtained by GPS.

For this analysis only aggregated data by villages were used.

\section{Statistical analysis}

\section{-Determining the smooth function (functional data) for each time series}

The time series of the observed weekly malaria incidence (the number of confirmed cases per week divided by the total population of the village) was determined for each of the 575 village. A square root transformation was applied to these incidence rates to stabilize the variance [4]. The functional data method $[4,5]$ states that the observed square root of incidence rate for a village $i$ at a week $j$ is the sum of a function on the week $j$ and an error term: 


$$
\left.y_{i j}=\sqrt{I n c_{i j}}=x_{i}\left(t_{j}\right)+\varepsilon_{i j} \quad \mathrm{i}=1, \ldots, 575, \mathrm{j}=1, \ldots, 261 \text { (eq. } 1\right)
$$

115 where $x_{i}$ is a regular (smooth) function which describes the temporal pattern of malaria 116 incidence in village $\mathrm{i}, \mathrm{t}_{\mathrm{j}}$ is the (continuous) calendar time, and $\varepsilon_{i j}$ is an error term representing

117 the difference between the function value and the observed data for village $\mathrm{i}$ at week $\mathrm{j}$.

118 The function $x_{i}$ is defined as follows:

$$
x_{i}(t)=\sum_{k=1}^{K} c_{i k} \varphi_{k}(t)
$$

120 where $\varphi_{k}$ are basis functions, $\mathrm{K}$ represents the total number of basis functions and $c_{i k}$ are the 121 coefficients obtained by the least squares method by minimizing the penalized error sum of squares.

$$
\left.\operatorname{SSE}\left(x_{i}\right)=\sum_{j=1}^{T}\left(y_{i j}-x_{i}\left(t_{j}\right)\right)^{2}+\lambda \int_{P}\left|x_{i}^{\prime \prime}(t)\right|^{2} d t, i=1, \ldots, 575 \text { (eq. } 3\right)
$$

124 where $\lambda$ is the smoothing parameters and $x_{i}^{\prime \prime}$ the second derivative function with $\int_{P}\left|x_{i}^{\prime \prime}(t)\right|^{2} d t<\infty$

126 To estimate the underlying function or functional data $x_{i}$, the family of basis functions $\varphi_{k}$,

127 their total number $\mathrm{K}$ and the smoothing parameter $\lambda$ should be chosen. The basis functions are 128 families of known and mathematically independent functions [4, 5]. Several basis functions are 129 possible but they have to be determined according to the nature of the data. In this work, we 130 used cubic B-splines to avoid periodic smoothing $[4,5]$. While the choice of the smoothing 131 parameter is very important, there is no universal rule for an optimal choice. However, a number 132 of criteria are available, including the generalized cross-validation (GCV), which we used [23]. 
134 To perform a hierarchical ascending clustering on smooth functions (functional data), a 135 proximity measure between them was necessary. Several dissimilarity measures are proposed

136 for time series. We focused on those based on value and behaviour that would adapt to the 137 functional data [23-27]. For those based only on values we had: the Euclidean distance in a 138 multidimensional space $\left(d_{E U C}\right)$, the Lp-metric estimating the surface between 2 functional data

$139\left(d_{F D A}\right)$, the dynamic time warping dissimilarity measure $\left(d_{D T W}\right)$ and the discrete wavelet 140 transformation dissimilarity measure $\left(d_{D W T}\right)$. To obtain dissimilarity measures based on 141 values and behaviour $\left(d_{C O R T}\right)$, a temporal correlation between 2 functional data, were 142 combined with each of the above dissimilarity measures based on values only [24, 26].

$$
d_{\text {CORT }}\left(x_{i}, x_{i^{\prime}}\right)=f_{\xi}\left[\operatorname{CORT}\left(x_{i}, x_{i^{\prime}}\right)\right] * d\left(x_{i}, x_{i^{\prime}}\right)
$$

$$
\operatorname{CORT}\left(x_{i}, x_{i^{\prime}}\right)=\frac{\sum_{t=1}^{T-1}\left(x_{i}(\mathrm{t}+1)-x_{i}(\mathrm{t})\right)\left(x_{i^{\prime}}(\mathrm{t}+1)-x_{i^{\prime}}(\mathrm{t})\right)}{\sqrt{\sum_{t=1}^{T-1}\left(x_{i}(\mathrm{t}+1)-x_{i}(\mathrm{t})\right)^{2}} \sqrt{\sum_{t=1}^{T-1}\left(x_{i^{\prime}}(\mathrm{t}+1)-x_{i^{\prime}}(\mathrm{t})\right)^{2}}}
$$

145 The adaptative function $f_{\xi}(u)=\frac{2}{1+\exp (\xi u)}, \xi \geq 0$ is used to adjust the percentage of

146 contribution of value and behavior according to the value of the parameter $\xi$.

\section{Table 1 here}

148 Table 1: The percentage of contribution in $d_{C O R T}$ dissimilarity measure according to the 149 parameter $\xi$.

\begin{tabular}{|l|l|l|}
\hline \multicolumn{1}{|c|}{$\xi$} & $\begin{array}{l}\text { Behavior } \\
\text { Contribution (\%) }\end{array}$ & $\begin{array}{l}\text { Values } \\
\text { Contribution (\%) }\end{array}$ \\
\hline 0 & 0 & 100 \\
\hline 1 & 46.2 & 53.7 \\
\hline 2 & 76.2 & 23.8 \\
\hline 3 & 90.5 & 9.4 \\
\hline$\geq 5$ & $\sim 100$ & $\sim 0$ \\
\hline
\end{tabular}


151 At this stage only the Euclidean distance and the dynamic time warping distance were

152 implemented in $\mathrm{R}$ package with this dissimilarity measure. We have written a $\mathrm{R}$ program to 153 estimate the functional Euclidean distance and the discrete wavelet transformation dissimilarity 154 based on valued and behaviour with the same formula above. When $\xi=0$ (Table 1) we had the 1554 dissimilarity measures based only on values, with the other values $\xi$, a total of 20 dissimilarity 156 measures were used in this analysis.

157 Thus, hierarchical ascending clustering (HAC) was performed on smooth functions with each 158 dissimilarity measure with Ward aggregation method [28]. The optimal number of clusters with 159 the best dissimilarity measure was guided by three validity indices used in a multidimensional 160 space for functional data [29-31]: Connectivity, Dunn, Silhouette and in addition the percentage 161 of inertia explained R2. We were looking for a classification (a result of HAC) with connectivity 162 index close to 0, high Dunn index, Silhouette and R2 close to 1. Thus, a Principal Component 163 Analysis PCA [32] was performed on these indices to choose the best classification.

164 In these two first step we worked on the functional data of the square root transformation of 165 observed time series, but for the following step we applied square transformations to have the 166 functional data corresponding to the observed time series.

167 After the clustering of the 575 functional data into Q clusters, we defined the functional data of

168 each cluster by $C_{q}(t), \mathrm{q}=1, \ldots, \mathrm{Q}$ being the cumulative weekly incidence of the villages 169 belonging to the cluster q. Then, their $95 \%$ point-wise confidence intervals were computed by 170 adding and subtracting two of the standard errors, that is, the square root of the sampling 171 variances, to the actual fit [4].

-Velocity and acceleration (slope and rate of change of the slope)

173 To further describe the malaria incidence pattern of each cluster, the first and second derivative 174 were determined for each functional data of a cluster. Thus, with mathematical properties of 
175 univariate function optimization [33] and one-dimensional kinematics in physics [34], seven

176 epidemiological indicators based on velocity and acceleration have been defined (Figure 1,

177 Table 2). These epidemiological indicators were: The beginning of seasonal outbreaks and the

178 start acceleration of the growth phase (A); The beginning of the pre-slowdown of the growth

179 phase (B); The deceleration's beginning of growth phase (C); The peak (D) also corresponding

180 after to the beginning of the acceleration of the decrease phase; The beginning of the

181 deceleration of the decrease phase (E); The beginning of the tail $(\mathrm{F})$; The end of the seasonal

182 outbreaks $(G)$. Finally, a Principal component analysis PCA was performed on the durations:

$183 \mathrm{AB}, \mathrm{AD}, \mathrm{CE}, \mathrm{DG}, \mathrm{FG}, \mathrm{BF}$ and $\mathrm{AG}$ for seasonal outbreaks of each cluster.

184 Table 2 here

\section{Table 2}

186 The description of epidemiological indicators and the determination of their corresponding date 187 for a functional cluster $C_{q}$

\begin{tabular}{|c|c|}
\hline Epidemiological indicators (EI) & Determination of EI's dates \\
\hline $\begin{array}{l}\text { Beginning of seasonal outbreaks } \\
\text { and the start acceleration of the } \\
\text { growth phase (A) }\end{array}$ & $t_{A}=\left\{\begin{array}{c}\text { first } t \text { such } C_{q}{ }^{\prime}(t)>0 \\
C_{q}{ }^{\prime \prime}(t)>0 \\
\text { on } 3 \text { weeks }\end{array}\right.$ \\
\hline $\begin{array}{l}\text { Beginning of the pre-slowdown of } \\
\text { the growth phase (B) }\end{array}$ & $t_{B}=\left\{\underset{t \operatorname{such} C_{q}^{\prime}(t)>0}{\operatorname{argmax}}\left(C_{q}^{\prime \prime}(t)\right)\right.$ \\
\hline $\begin{array}{l}\text { deceleration's beginning of } \\
\text { growth phase }(\mathrm{C})\end{array}$ & $t_{C}=\left\{\underset{t \operatorname{such} C_{q}{ }^{\prime \prime}(t)=0}{\operatorname{argmax}}\left(C_{q}{ }^{\prime}(t)\right)\right.$ \\
\hline $\begin{array}{l}\text { Peak of seasonal outbreaks and } \\
\text { beginning of the acceleration of } \\
\text { the decrease phase (D) }\end{array}$ & $t_{D}=\left\{\begin{array}{l}C_{q}{ }^{\prime}(t)=0 \\
C_{q}{ }^{\prime \prime}(t)<0\end{array}\right.$ \\
\hline $\begin{array}{l}\text { Beginning of the deceleration of } \\
\text { the decrease phase }(E)\end{array}$ & $t_{E}=\left\{\underset{t \operatorname{such} C_{q}^{\prime \prime}(t)=0}{\operatorname{argmin}}\left(C_{q}{ }^{\prime}(t)\right)\right.$ \\
\hline $\begin{array}{l}\text { Beginning of the tail of seasonal } \\
\text { outbreaks }(F)\end{array}$ & $t_{F}=\left\{\underset{t \operatorname{such} C_{q}^{\prime}(t)<0}{\operatorname{argmax}}\left(C_{q}{ }^{\prime \prime}(t)\right)\right.$ \\
\hline End of seasonal outbreaks $(\mathrm{G})$ & $t_{G}=\left\{\begin{array}{c}\text { first } t \text { such } C_{q}{ }^{\prime}(t)=0 \\
\text { on } 3 \text { weeks }\end{array}\right.$ \\
\hline
\end{tabular}




\section{Figure 1}

192 A graphical example for the seven epidemiological indicators: the beginning of seasonal 193 outbreaks and the start acceleration of the growth phase (A); the beginning of the pre-slowdown 194 of the growth phase (B); the deceleration's beginning of growth phase (C); the peak (D) also 195 corresponding after to the beginning of the acceleration of the decrease phase; the beginning of 196 the deceleration of the decrease phase (E); the beginning of the tail $(\mathrm{F})$; the end of the seasonal 197 outbreaks (G); functional incidence in red line, functional velocity in black bold line (first 198 derivative) and functional acceleration in black discontinuous line (second derivative).

199

200 Results

-From observed to smoothed malaria incidence

202 The observed incidence ranged from 0 to 16,667 cases/100,000 person-weeks (Figure 2, Panel

203 A) at the village level. The maximum seasonal outbreaks peaks ranged from 4,478 and 16,667

204 cases/100,000 person-weeks. The search for the optimal number of basis function and the 205 optimal smoothing parameter gave $K_{o p t}=110$ and $\lambda_{\text {opt }}=103$ which minimized the error by GCV equal to 11.8 with a standard deviation of $\sigma=0.12$. Smoothed malaria incidence ranged 207 from 0 to 2,296 cases/100,000 person-weeks with seasonal outbreaks peaks between 541 and 208 2,296 cases/100,000 person-weeks (Figure 2, Panel B).

Figure 2 here

\section{$210 \quad$ Figure 2}

211 Weekly malaria incidence evolution for each village from January 2008 to December 2012:

212 observed time series (Panel A) and smoothed functions of time series (Panel B) 
215 Three clusters with the DTWCORT1 dissimilarity measure were chosen based on the principal 216 component analysis performed on validity indices and dissimilarity measures for 3 and 4 217 number classes (Additional file 1, Additional file 2).

\section{$218 \quad$ Figure 3 here}

\section{Figure 3}

220 Principal component analysis on validity indices and dissimilarity measures for 3 and 4 number 221 clusters: validity indices map (Variables, Panel A), dissimilarity measures map (Individuals, 222 Panel B)

Indeed, the dimension 1 represented high Dunn index and silhouettes, and low connectivity by the clusters (Figure 3, Panel A). The best classification should therefore be located in the upper right of the factorial plane of the dissimilarity measures and the number of clusters (Figure 3, Panel B). The DTWCORT1 dissimilarity measure took account $46.2 \%$ of the temporal correlation between functional data and $53.7 \%$ of the geometric distance.

\section{Figure 4 here}

\section{$231 \quad$ Figure 4}

232 The spatial distribution of malaria incidence patterns in the area study (Panel A) and smoothed 233 functions for each malaria incidence pattern (Panel B): Senegal map and the location of the

234 study area pointed by the arrow, high incidence pattern in red line, intermediate incidence 235 pattern in blue line and low incidence pattern in green line.

237 The high incidence pattern (high pattern) consisted of a set of 12 villages with the highest 238 observed average incidence over the 5 year study period (114 cases/1000 person-years), mainly 239 located in the southern part of the study area (Figure 4, Panel A). Its smoothed seasonal 240 outbreaks peaks ranged from 233 to 884 cases/100,000 person-weeks (Table 3). 
241 The intermediate incidence pattern (intermediate pattern) included 97 villages had 13

242 cases/1000 person-years as observed average incidence over the study period, located both in

243 the southern and northern part of the study area. Its smoothed seasonal outbreaks peaks ranged

244 from 26 to 131 cases/100,000 person-weeks (Table 3).

245 The low incidence pattern (low pattern) consisted of a set of 466 villages with the lowest

246 average incidence over study period (2.6 cases/1000 person-years), mainly located in the

247 northern part of the study area. Its smoothed seasonal outbreaks peaks ranged from 7 to 34

248 cases/100,000 person-weeks (Table 3).

249 The two higher incidence patterns (high and intermediate) correspond to $23 \%$ of the population

250 and $19 \%$ of villages.

Table 3 here

\section{Table 3}

253 Incidence description of Malaria incidence patterns: the type of pattern, their number villages 254 and their ranges peaks of smoothed seasonal outbreaks and their observed cumulative incidence 255 over the 5 years of study period

\begin{tabular}{|l|l|l|l|}
\hline $\begin{array}{l}\text { Malaria } \\
\text { incidence } \\
\text { Patterns }\end{array}$ & $\begin{array}{l}\text { Number of } \\
\text { villages }\end{array}$ & $\begin{array}{l}\text { Range peaks of smoothed } \\
\text { seasonal outbreaks } \\
\text { (cases/100,000 person- } \\
\text { weeks) }\end{array}$ & $\begin{array}{l}\text { Observed cumulative } \\
\text { incidence over the 5 } \\
\text { year study period } \\
\text { (cases/1000 } \\
\text { person_years) }\end{array}$ \\
\hline High & 12 & $233-884$ & 114 \\
\hline Intermediate & 97 & $26-131$ & 13 \\
\hline Low & 466 & $7-34$ & 2.6 \\
\hline
\end{tabular}

Figure 5 here

\section{Figure 5}

259 Weekly observed malaria incidence in black solid line, smoothed malaria incidence in color

260 solid line and smooth $95 \%$ point-wise confidence intervals in discontinuous color line : high 261 incidence pattern in red (Panel A), intermediate incidence pattern in blue (Panel B) and low 262 incidence pattern in green (Panel C). 
264 The observed incidence of the patterns, their smoothed incidence and their 95\% point-wise 265 confidence intervals of smoothing were highlighted for each malaria incidence pattern (Figure 266 5). In all the patterns, the observed incidence rates were in the ranges except for a few peaks in 267 the high pattern (Figure 5).

\section{-Velocity and acceleration of malaria incidence patterns}

The velocity curve of each pattern (Additional file 3, Panel A) represented the variation over time of the slope and the acceleration curve of each pattern (Additional file 3, Panel B) represented the rate evolution of change of the slope. The velocities and accelerations of the high pattern were higher, followed by those of the intermediate pattern and those of the low pattern were the lowest (Additional file 3).

274 The epidemiological indicators determined using the velocity and acceleration functions (Figure 6) as described in the methodology showed that the low pattern was always the one that started (A) the latest. The high pattern started earlier 3 times during the 5 seasonal outbreaks and the intermediate pattern twice. In addition, seasonal outbreaks of the high and intermediate patterns usually started between April and June with a lag between 1 to 3 weeks. Those of the low pattern started between June and July with a delay between 4 and 9 weeks after the 280 intermediate pattern, and with a lag between 3 and 10 weeks after the high pattern (Table 4).

281 The phases of pre-slowdown (B) and slowdown (C) of epidemic's growth started mainly 282 between August and September for all patterns with a lag between 1 and 2 weeks. Then, the 283 peak (D) of seasonal outbreaks for all patterns, occurred between October and November almost 284 the same time or with maximum 1 week of lag. The beginning of the deceleration phase of the 285 decrease (E) occurred between November and December for all patterns, almost at the same 286 time or with maximum 1 week of lag. The exception of the latter point was that the E of seasonal 
outbreaks beginning in 2009 and 2010 of the high pattern and those beginning in 2010 of the intermediate pattern began between January and February of their following years respectively (Table 4).

The tails (F) of seasonal outbreaks for low pattern were the earliest, starting in December; those

291 of high pattern were the latest, starting between December and March. Those of intermediate

292 pattern followed those of high pattern and started between December and February. Moreover,

293 the lag between high and low pattern was from 1 to 11 weeks, those between high and

294 intermediate pattern was from 1 to 9 weeks and those between intermediate and low pattern 295 was from 0 to 7 weeks (Table 4).

296 The end of seasonal outbreaks $(\mathrm{G})$ for the high and intermediate pattern occurred between

297 March and May with a lag from 0 to 7 weeks; those of low pattern occurred the earliest between

298 February and March with a lag from 3 to 13 weeks before high pattern and a lag from 3 to 9

299 weeks before the intermediate pattern.

$300 \quad$ Figure 6 here

\section{$301 \quad$ Figure 6}

302 Smoothed incidence in color solid line, their velocity in black bold solid line, their acceleration 303 in black discontinuous line and the epidemiological indicator of their seasonal outbreaks (A: 304 onset, B: near slowdown of growth, C: beginning slowdown of growth, D: Peak, E: beginning 305 acceleration of decline, F: beginning of tail, G: end ): high incidence pattern in red (Panel A), 306 intermediate incidence pattern in blue (Panel B) and low incidence pattern in green (Panel C). 
312 Table 4 : The epidemiological indicators (EI) and their characteristics over seasonal outbreaks

\begin{tabular}{|c|c|c|c|c|c|c|c|}
\hline $\begin{array}{l}\text { Start } \\
\text { year } \\
\text { seasonal } \\
\text { outbreak } \\
\end{array}$ & EI & DateHigh & DateInter & DateLow & WeekHigh & WeekInter & WeekLow \\
\hline 2008 & A & $13 / 05 / 2008$ & $29 / 04 / 2008$ & $17 / 06 / 2008$ & 20 & 18 & 25 \\
\hline 2009 & A & $19 / 05 / 2009$ & $26 / 05 / 2009$ & $28 / 07 / 2009$ & 21 & 22 & 31 \\
\hline 2010 & A & $08 / 06 / 2010$ & $01 / 06 / 2010$ & $29 / 06 / 2010$ & 24 & 23 & 27 \\
\hline 2011 & A & $26 / 04 / 2011$ & $10 / 05 / 2011$ & $14 / 06 / 2011$ & 18 & 20 & 25 \\
\hline 2012 & A & $03 / 04 / 2012$ & $24 / 04 / 2012$ & $29 / 05 / 2012$ & 15 & 18 & 23 \\
\hline 2008 & B & $09 / 09 / 2008$ & $02 / 09 / 2008$ & $26 / 08 / 2008$ & 37 & 36 & 35 \\
\hline 2009 & B & $25 / 08 / 2009$ & 08/09/2009 & $25 / 08 / 2009$ & 35 & 37 & 35 \\
\hline 2010 & B & $14 / 09 / 2010$ & $31 / 08 / 2010$ & $07 / 09 / 2010$ & 38 & 36 & 37 \\
\hline 2011 & B & $23 / 08 / 2011$ & $23 / 08 / 2011$ & $23 / 08 / 2011$ & 35 & 35 & 35 \\
\hline 2012 & $\mathrm{~B}$ & $28 / 08 / 2012$ & $28 / 08 / 2012$ & $28 / 08 / 2012$ & 36 & 36 & 36 \\
\hline 2008 & $\mathrm{C}$ & $30 / 09 / 2008$ & $23 / 09 / 2008$ & $23 / 09 / 2008$ & 40 & 39 & 39 \\
\hline 2009 & $\mathrm{C}$ & $22 / 09 / 2009$ & $22 / 09 / 2009$ & $15 / 09 / 2009$ & 39 & 39 & 38 \\
\hline 2010 & $\mathrm{C}$ & $05 / 10 / 2010$ & $28 / 09 / 2010$ & $28 / 09 / 2010$ & 41 & 40 & 40 \\
\hline 2011 & $\mathrm{C}$ & $13 / 09 / 2011$ & $20 / 09 / 2011$ & $20 / 09 / 2011$ & 38 & 39 & 39 \\
\hline 2012 & $\mathrm{C}$ & $18 / 09 / 2012$ & $18 / 09 / 2012$ & $25 / 09 / 2012$ & 39 & 39 & 40 \\
\hline 2008 & $\mathrm{D}$ & $28 / 10 / 2008$ & $21 / 10 / 2008$ & $21 / 10 / 2008$ & 44 & 43 & 43 \\
\hline 2009 & $\mathrm{D}$ & $27 / 10 / 2009$ & $20 / 10 / 2009$ & $20 / 10 / 2009$ & 44 & 43 & 43 \\
\hline 2010 & $\mathrm{D}$ & $02 / 11 / 2010$ & $26 / 10 / 2010$ & $02 / 11 / 2010$ & 45 & 44 & 45 \\
\hline 2011 & $\mathrm{D}$ & $11 / 10 / 2011$ & $25 / 10 / 2011$ & $18 / 10 / 2011$ & 42 & 44 & 43 \\
\hline 2012 & $\mathrm{D}$ & $23 / 10 / 2012$ & $23 / 10 / 2012$ & $30 / 10 / 2012$ & 44 & 44 & 45 \\
\hline 2008 & $\mathrm{E}$ & $02 / 12 / 2008$ & $02 / 12 / 2008$ & $25 / 11 / 2008$ & 49 & 49 & 48 \\
\hline 2009 & $\mathrm{E}$ & $16 / 02 / 2010$ & $01 / 12 / 2009$ & $08 / 12 / 2009$ & 8 & 49 & 50 \\
\hline 2010 & $\mathrm{E}$ & $18 / 01 / 2011$ & $18 / 01 / 2011$ & $30 / 11 / 2010$ & 4 & 4 & 49 \\
\hline 2011 & $\mathrm{E}$ & $29 / 11 / 2011$ & $29 / 11 / 2011$ & $22 / 11 / 2011$ & 49 & 49 & 48 \\
\hline 2012 & $\mathrm{E}$ & $27 / 11 / 2012$ & $20 / 11 / 2012$ & $27 / 11 / 2012$ & 49 & 48 & 49 \\
\hline 2008 & $\mathrm{~F}$ & $06 / 01 / 2009$ & $23 / 12 / 2008$ & $23 / 12 / 2008$ & 2 & 52 & 52 \\
\hline 2009 & $\mathrm{~F}$ & $16 / 03 / 2010$ & $12 / 01 / 2010$ & $29 / 12 / 2009$ & 12 & 3 & 1 \\
\hline 2010 & $\mathrm{~F}$ & $15 / 02 / 2011$ & $08 / 02 / 2011$ & $21 / 12 / 2010$ & 8 & 7 & 52 \\
\hline 2011 & $\mathrm{~F}$ & $20 / 12 / 2011$ & $13 / 12 / 2011$ & $13 / 12 / 2011$ & 52 & 51 & 51 \\
\hline 2008 & G & $12 / 05 / 2009$ & $24 / 03 / 2009$ & $10 / 02 / 2009$ & 20 & 13 & 7 \\
\hline 2009 & G & $11 / 05 / 2010$ & $04 / 05 / 2010$ & $02 / 03 / 2010$ & 20 & 19 & 10 \\
\hline 2010 & G & $26 / 04 / 2011$ & $26 / 04 / 2011$ & $22 / 03 / 2011$ & 18 & 18 & 13 \\
\hline 2011 & G & $20 / 03 / 2012$ & $03 / 04 / 2012$ & $28 / 02 / 2012$ & 13 & 15 & 10 \\
\hline
\end{tabular}

313

314 The seasonal outbreaks for all patterns were further described with the PCA performed on the

315 durations between selected relevant epidemiological indicators (Figure 7, Panel A). These were:

316 the duration of growth's acceleration phase (AB); those between start and peak (AD); those

317 between slowdown of growth and decline (CE) indicating the width of the peak area; those 
318 between peak and the end (DG); those between the tail and the end of seasonal outbreaks (FG);

319 those between pre-slowdown and the tail (BF) indicating the width of epidemic's body; those

320 between the start and the end of epidemic episodes (AG) indicating the duration of the seasonal

321 outbreaks.

$322 \quad$ Figure 7 here

$323 \quad$ Figure 7

324 Principal component analysis on duration epidemiological indicator and seasonal outbreaks of

325 the patterns: epidemiological indicator map (Variables, Panel A), seasonal outbreaks of the 326 patterns map (Individuals, Panel B)

328 The result of PCA (Figure 7, Additional file 4) showed that the seasonal outbreaks (Figure 7,

329 Panel B) of high pattern starting since $2009(2009 \mathrm{H})$ and $2010(2010 \mathrm{H})$, and those of the 330 intermediate pattern starting since 2010 (2010I) were mainly characterized by a high BF and

331 CE, and also by a low FG.

332 In addition, the seasonal outbreaks of low pattern were characterized by low AG, DG AD and

333 AB. The seasonal outbreaks starting since 2008 and 2011 for high and intermediate patterns 334 (2008H, 2008I, 2011I, and 2011H) were mainly characterized by high FG on the one hand and 335 on the other hand by low BF and CE. In addition, 2008H, 2009I and 2011H were also 336 characterized by a high $\mathrm{AG}, \mathrm{AD}, \mathrm{AB}$, and $\mathrm{DG}$.

\section{Discussion}

339 The approach used here led to the identification of three distinct patterns for the time-course of

340 malaria incidence in a village, by taking into account dynamics of malaria incidence over the 341 whole study period. 
In the estimation of the smooth functions (functional data) we used B-Spline cubic basis

343 function. Indeed, some other basis functions were available as the Fourier basis for periodic

344 data. We used B-spline cubic basis, because, even if seasonal outbreaks occurred with a

345 periodicity, intensities were different. However, in our context, there are no difference between

346 both basis, and, in this case, B-spline are more tractable $[4,5,7]$.

347 The choice of dissimilarity measure for functional data is important before applying an 348 unsupervised classification method, to have well-separated classes. Some other dissimilarity 349 measures could be added [35]. We preferred to limit them on the measures less dependent to 350 the autocorrelation structure. Indeed, the smoothing approach of functional data may impact 351 the autocorrelation structure. For the choice of validity indices, we preferred also to concentrate 352 on a small number of those assessing the separability (Dunn), compactness (Connectivity), the 353 quality of clustering for villages in average (Silhouette) $[30,31]$ and percentage of inertia $\left(\mathrm{R}^{2}\right)$.

354 The detection methods of transmission foci or hotspots have been defined differently in the 355 literature[36]. There are methods that define them from an incidence or prevalence threshold 356 [14] others with biological parameter [37] and others from scanning algorithm [9] or 357 geostatistical approaches [8]. In addition, spatial and temporal analyzes were often based on 358 the fragmentation of the study period. Indeed in some researches, these temporal divisions were 359 based on the calendar (month, year) or the rainy seasons, in other works of temporal 360 fragmentation methods were based on algorithms such as change point analysis [14-18, 38, 39].

361 In our study, hotspot identification was made by taking account not only the value of the 362 incidence but also the dynamic of the malaria incidence over the whole study period hence the 363 malaria incidence pattern name. Consequently, this method can be used to distinguish two 364 spatial units that have the same level of incidence or the same number of cases, but with 365 different dynamics. Indeed, an epidemic that starts with a high intensity and declines over time 366 is different from another that increases over time, leading to different control strategies. 
With our approach, characterizations of the seasonal outbreaks have been made using the 368 velocities and accelerations of the malaria incidence pattern. This allowed us to define epidemiological indicators for which seasonal outbreaks were further described. Following this approach, one of the results showed that low incidence pattern was the latest to start and the earliest to end seasonal outbreaks, all incidence pattern reached their seasonal peaks almost in 372 the same time. In the case of other countries, different results can be found with these epidemiological indicators. In addition, the seasonal outbreaks 2009H, 2010H and 2010I were remarkable. The focus analyzed on their velocity and acceleration showed an outbreak rebound. This can have impact on their high width of peak area (CE) and body (BF). Despite this, their durations tail were low, consequently the duration of the outbreak as well.

377 Furthermore, previous researches had focused on the search for epidemic thresholds and stratification into intensity levels of different epidemics, particularly in the field of influenza surveillance and acute respiratory infection in Europe [40-44]. However, as stated by numerous authors, there was no automatic and objective way to compare thresholds and intensity levels

381 across the countries studied. Although the epidemiological contexts are not the same with 382 malaria, we were able to introduce an approach based on functional data allowing the smoothing 383 of the time series of the village incidence by a single smoothing parameter and a single number 384 of basis functions. Thereby, this allowed a possible comparison between them because they had 385 the same scale [4]. For this purpose, even if this was not our main objective, we could define 386 the starting date of an outbreak as the time from which the velocity and acceleration functions 387 are strictly positive for at least 3 consecutive weeks (indeed, the first symptoms of malaria 388 appear 1 to 4 weeks after infection [45]). Thus, this approach can be applied in other diseases contexts.

This work showed a relatively small number of high incidence villages, which were adjacent to 391 low incidence villages. It may be useful to investigate social and environmental factors that 
may be associated with locally high incidence (e.g. proximity to water bodies, use of control

393 measures,...). The two higher incidence patterns correspond to $23 \%$ of the population.

394 Awareness of these trends may assist district health teams to strengthen control in high risk 395 communities and guide targeted intervention, and our results suggest that a targeted strategy 396 might need to include about $20 \%$ of the population.

\section{Conclusion}

398 Functional data analysis can be used to classify communities based on time series of malaria 399 incidence, and to identify high incidence communities. Indicators can be derived from the fitted 400 functions which characterize the timing of outbreaks. These tools may help to better target 401 control measures.

402

403 Ethics

404 The protocols for the field studies were approved by Senegal's Conseil National pour la 405 Recherche en Santé and the ethics committee of the London School of Hygiene \& Tropical 406 Medicine. The SMC trial were registered at www.clinicaltrials.gov, number NCT 00712374.

\section{Consent for publication}

408 All authors have read and approved the manuscript.

\section{Availability of data and materials}

410 The datasets analyzed during the current study are available from the corresponding author on 411 reasonable request.

\section{Competing interests}

413 The authors declare that they have no competing interests. 
415 Not applicable in our study.

\section{Authors' contributions}

417 SD and JG designed the study, performed data processing, the statistical analysis and 418 interpretation, and wrote the first draft of the article; PiM et AG contributed to the statistical 419 analysis; KS contributed to the data processing; EB, BC, CS and PaM coordinated the data 420 collection and validation; PC, PaM contributed to the interpretation of the results. All authors 421 read and approved the final manuscript.

\section{Acknowledgments}

423 We thank the public health network "Reseau doctoral en santé publique" coordinated by the 424 EHESP (School for Higher Studies in Public Health) for supporting the thesis project of SD. We thank the NGO PROSPECTIVE \& COOPERATION for collaboration. Lastly, we thank Arianne Dorval for comments.

\section{References}

1. World Health Organization, Global Malaria Programme, World Health Organization. A 431 framework for malaria elimination. 2017.

432 http://apps.who.int/iris/bitstream/10665/254761/1/9789241511988-eng.pdf. Accessed 28 Oct 4332019.

434 2. Ferraty F, Vieu P. Richesse et complexité des données fonctionnelles. Revue Modulad. 435 2011;43:25-43. http://www.modulad.fr/archives/numero-43/VIEU/2-Vieu.pdf.

436 3. Ferraty F. Modélisation statistique pour variables aléatoires fonctionnelles: théorie et 437 application. Habilitationa diriger des recherches, Université Paul Sabatier. 2003.

438 https://www.math.univ-toulouse.fr/ besse/pub/chapBC.ps.

439 4. Ramsay JO, Silverman BW. Functional data analysis. 2nd ed. New York: Springer; 2005. 
442 6. Ramsay JO, Silverman BW, Ramsay JO, Silverman BW. Applied Functional Data

443 Analysis: Methods and Case Studies. Springer; 2002.

444 7. Ullah S, Finch CF. Applications of functional data analysis: A systematic review. BMC

445 Med Res Methodol. 2013;13:43. doi:10.1186/1471-2288-13-43.

446 8. Diggle PJ, Tawn JA, Moyeed RA. Model-based geostatistics. :52.

447 9. Kulldorff M. A spatial scan statistic. Communications in Statistics - Theory and Methods. 448 1997;26:1481-96. doi:10.1080/03610929708831995.

449 10. Gaudart J, Graffeo N, Coulibaly D, Barbet G, Rebaudet S, Dessay N, et al. SPODT : An $R$ 450 Package to Perform Spatial Partitioning. Journal of Statistical Software. 2015;63.

451 doi:10.18637/jss.v063.i16.

452 11. Bejon P, Williams TN, Nyundo C, Hay SI, Benz D, Gething PW, et al. A micro453 epidemiological analysis of febrile malaria in Coastal Kenya showing hotspots within 454 hotspots. eLife. 2014;3:e02130. doi:10.7554/eLife.02130.

455

456

457

458

459

460

461

462

463

464

465

466

467

468

469

470

471

472

473

474

475

476

477

12. Platt A, Obala AA, MacIntyre C, Otsyula B, Meara WPO. Dynamic malaria hotspots in an open cohort in western Kenya. Scientific Reports. 2018;8:647. doi:10.1038/s41598-01713801-6.

13. Sallah K, Giorgi R, Ba EH, Piarroux M, Piarroux R, Griffiths K, et al. Targeting hotspots to reduce transmission of malaria in Senegal: modeling of the effects of human mobility. 2018. doi:10.1101/403626.

14. Landier J, Parker DM, Thu AM, Lwin KM, Delmas G, Nosten FH, et al. Effect of generalised access to early diagnosis and treatment and targeted mass drug administration on Plasmodium falciparum malaria in Eastern Myanmar: an observational study of a regional elimination programme. The Lancet. 2018;0. doi:10.1016/S0140-6736(18)30792-X.

15. Bejon P, Williams TN, Liljander A, Noor AM, Wambua J, Ogada E, et al. Stable and Unstable Malaria Hotspots in Longitudinal Cohort Studies in Kenya. PLoS Med. 2010;7. doi:10.1371/journal.pmed.1000304.

16. Coulibaly D, Travassos MA, Tolo Y, Laurens MB, Kone AK, Traore K, et al. SpatioTemporal Dynamics of Asymptomatic Malaria: Bridging the Gap Between Annual Malaria Resurgences in a Sahelian Environment. The American Journal of Tropical Medicine and Hygiene. 2017;97:1761-9. doi:10.4269/ajtmh.17-0074.

17. Ouedraogo B, Inoue Y, Kambiré A, Sallah K, Dieng S, Tine R, et al. Spatio-temporal dynamic of malaria in Ouagadougou, Burkina Faso, 2011-2015. Malaria Journal. 2018;17. doi:10.1186/s12936-018-2280-y.

18. Sissoko MS, Sissoko K, Kamate B, Samake Y, Goita S, Dabo A, et al. Temporal dynamic of malaria in a suburban area along the Niger River. Malar J. 2017;16. doi:10.1186/s12936017-2068-5. 
19. Santos-Vega M, Bouma MJ, Kohli V, Pascual M. Population Density, Climate Variables and Poverty Synergistically Structure Spatial Risk in Urban Malaria in India. PLOS Neglected Tropical Diseases. 2016;10:e0005155. doi:10.1371/journal.pntd.0005155.

20. Cissé B, Ba EH, Sokhna C, NDiaye JL, Gomis JF, Dial Y, et al. Effectiveness of Seasonal Malaria Chemoprevention in Children under Ten Years of Age in Senegal: A Stepped-Wedge Cluster-Randomised Trial. PLOS Medicine. 2016;13:e1002175. doi:10.1371/journal.pmed.1002175.

21. Bâ E-H, Pitt C, Dial Y, Faye SL, Cairns M, Faye E, et al. Implementation, coverage and equity of large-scale door-to-door delivery of Seasonal Malaria Chemoprevention (SMC) to children under 10 in Senegal. Sci Rep. 2018;8. doi:10.1038/s41598-018-23878-2.

22. Bulletin Epidemiologique ANNUEL 2018 du Paludisme au SENEGAL (www.pnlp.sn).

23. Febrero-Bande M, de la Fuente MO, others. Statistical computing in functional data analysis: The R package fda. usc. Journal of Statistical Software. 2012;51:1-28.

https://www.jstatsoft.org/htaccess.php?volume=51\&type=i\&issue=04\&paper=true. Accessed 13 Sep 2017.

24. Douzal-Chouakria A, Amblard C. Classification trees for time series. Pattern Recognition. 2012;45:1076-91. doi:10.1016/j.patcog.2011.08.018.

25. Giorgino T. Computing and Visualizing Dynamic Time Warping Alignments in $R$ : The dtw Package. J Stat Soft. 2009;31. doi:10.18637/jss.v031.i07.

26. Chouakria AD, Nagabhushan PN. Adaptive dissimilarity index for measuring time series proximity. ADAC. 2007;1:5-21. doi:10.1007/s11634-006-0004-6.

27. Montero P, Vilar JA. TSclust : An $R$ Package for Time Series Clustering. J Stat Soft. 2014;62. doi:10.18637/jss.v062.i01.

28. Murtagh F, Legendre P. Ward's Hierarchical Agglomerative Clustering Method: Which Algorithms Implement Ward's Criterion? J Classif. 2014;31:274-95. doi:10.1007/s00357014-9161-z.

29. Dunn† JC. Well-Separated Clusters and Optimal Fuzzy Partitions. Journal of Cybernetics. 1974;4:95-104. doi:10.1080/01969727408546059.

30. Rousseeuw PJ. Silhouettes: A graphical aid to the interpretation and validation of cluster analysis. Journal of Computational and Applied Mathematics. 1987;20:53-65. doi:10.1016/0377-0427(87)90125-7.

31. Malouche D. Méthodes de classifications. 2013. http://math.univbpclermont.fr/DoWellB/docs/malouche/methodes_classifications_CF_Juin2013.pdf.

32. Husson F, Lê S, Pagès J. Exploratory multivariate analysis by example using R. Boca Raton: CRC Press; 2011.

33. Guichard D. 5. Curve Sketching. https://www.whitman.edu/mathematics/calculus_online/chapter05.html. Accessed 19 Nov 2019. 
34. Sunil Kumar Singh. Acceleration and deceleration - Kinematics fundamentals - OpenStax CNX. 2010. http://cnx.org/contents/f25d0bfc-5f61-411b-bcee-be8187ad5cc7@10. Accessed

51818 Nov 2019.

35. Montero P, Vilar JA. Tsclust: An r package for time series clustering. Journal of. 2014.

36. McKay HS, Lessler J, Moore SM, Azman AS. What is a Hotspot Anyway? The American Journal of Tropical Medicine and Hygiene. 2017;96:1270-3. doi:10.4269/ajtmh.16-0427.

37. Bousema T, Griffin JT, Sauerwein RW, Smith DL, Churcher TS, Takken W, et al. Hitting Hotspots: Spatial Targeting of Malaria for Control and Elimination. PLoS Medicine. 2012;9:e1001165. doi:10.1371/journal.pmed.1001165.

38. Gaudart J, Poudiougou B, Dicko A, Ranque S, Toure O, Sagara I, et al. Space-time clustering of childhood malaria at the household level: a dynamic cohort in a Mali village. BMC Public Health. 2006;6. doi:10.1186/1471-2458-6-286.

39. Rouamba T, Nakanabo-Diallo S, Derra K, Rouamba E, Kazienga A, Inoue Y, et al. Socioeconomic and environmental factors associated with malaria hotspots in the Nanoro demographic surveillance area, Burkina Faso. BMC Public Health. 2019;19. doi:10.1186/s12889-019-6565-z.

40. Fleming DM, Zambon M, Bartelds AIM, de Jong JC. The duration and magnitude of influenza epidemics: A study of surveillance data from sentinel general practices in England, Wales and the Netherlands. 1999;:7.

41. Rakocevic B, Grgurevic A, Trajkovic G, Mugosa B, Sipetic Grujicic S, Medenica S, et al. Influenza surveillance: determining the epidemic threshold for influenza by using the Moving Epidemic Method (MEM), Montenegro, 2010/11 to 2017/18 influenza seasons. Euro Surveill. 2019;24. doi:10.2807/1560-7917.ES.2019.24.12.1800042.

539 42. Teklehaimanot HD, Schwartz J, Teklehaimanot A, Lipsitch M. Alert Threshold Algorithms and Malaria Epidemic Detection. Emerg Infect Dis. 2004;10:1220-6. doi:10.3201/eid1007.030722.

43. Vega T, Lozano JE, Meerhoff T, Snacken R, Beauté J, Jorgensen P, et al. Influenza surveillance in Europe: comparing intensity levels calculated using the moving epidemic method. Influenza and Other Respiratory Viruses. 2015;9:234-46. doi:10.1111/irv.12330. surveillance in Europe: establishing epidemic thresholds by the Moving Epidemic Method. Influenza and Other Respiratory Viruses. 2013;7:546-58. doi:10.1111/j.17502659.2012.00422.x. 


\section{Additional fille}

\section{Additional file 1.}

556 Additional file 1.docx

557 Validity indices performed on each hierarchical ascending clustering's results for 3 and 4

558 clusters: Connectivity, Dunn, Silhouette and the percentage of inertia explained R2

\section{Additional file 2.}

Additional file 2.jpeg

Dendrogram resulting of hierarchical clustering on smooth function with DTWCORT1 dissimilarity measure: 12 villages with high incidence pattern (red), 97 villages with intermediate incidence pattern (blue border) and 466 with a low incidence pattern (green 566 border)

\section{Additional file 3 .}

Additional file 3.jpeg

570

571

572

573

574

The velocity (Panel A) and the acceleration (Panel B) dynamics of malaria incidence patterns: high incidence pattern in red line, intermediate incidence pattern in blue line and low incidence pattern in green line.

\section{Additional file 4.}

\section{Additional file 4.docx}

The PCA results on duration epidemiological indicator (EI) and seasonal outbreaks of the patterns: the PCA indicator (correlation between EI and dimensions, $\cos 2$ measuring the quality of projection of EI in the map factor, the percentage of contribution and the coordinates of seasonal outbreaks); dimensions or axis of PCA. 


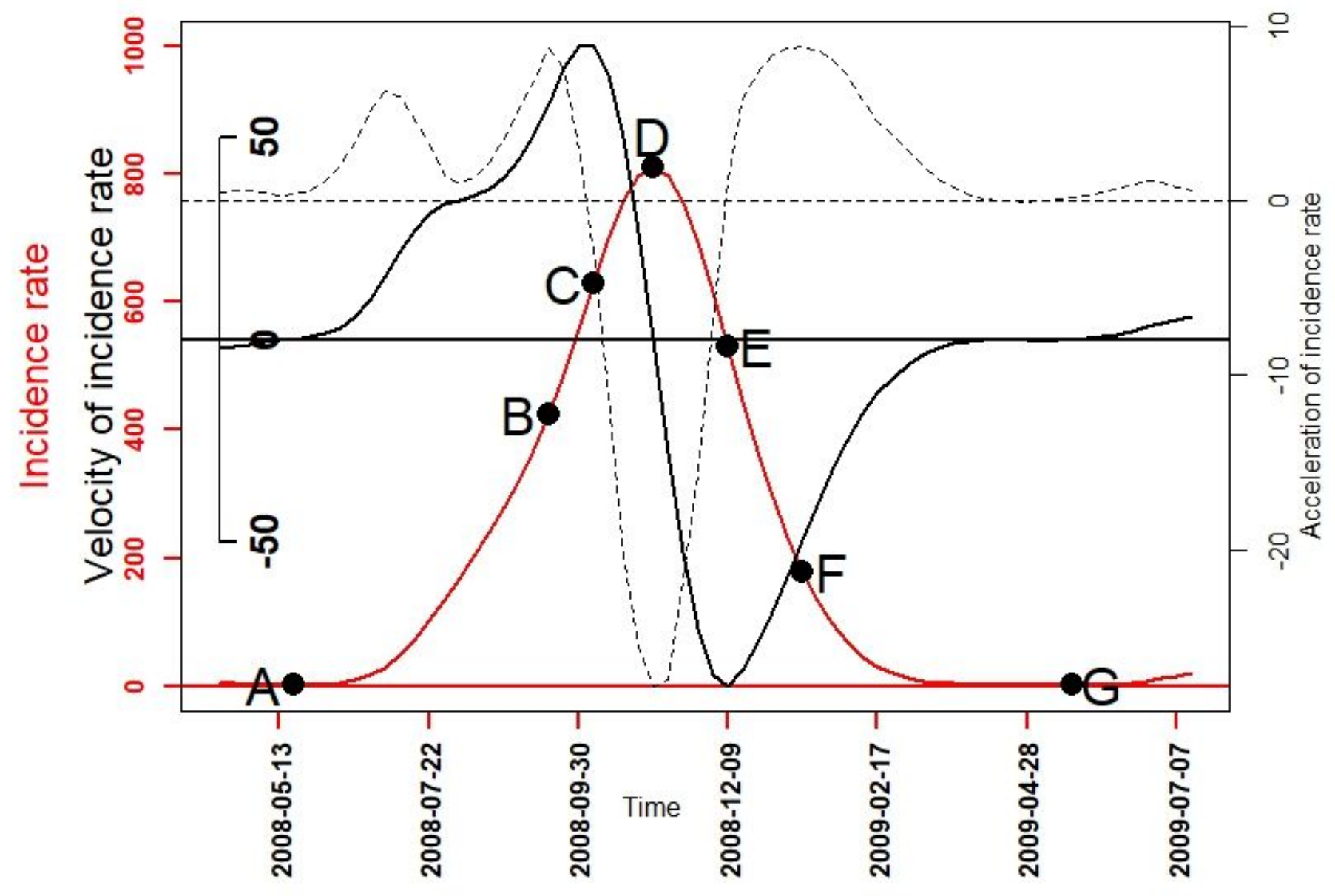

Figure 1

A graphical example for the seven epidemiological indicators: the beginning of seasonal outbreaks and the start acceleration of the growth phase (A); the beginning of the pre-slowdown of the growth phase (B); the deceleration's beginning of growth phase (C); the peak (D) also corresponding after to the beginning of the acceleration of the decrease phase; the beginning of the deceleration of the decrease phase $(\mathrm{E})$; the beginning of the tail $(F)$; the end of the seasonal outbreaks $(G)$; functional incidence in red line, functional velocity in black bold line (first derivative) and functional acceleration in black discontinuous line (second derivative). 
Panel A

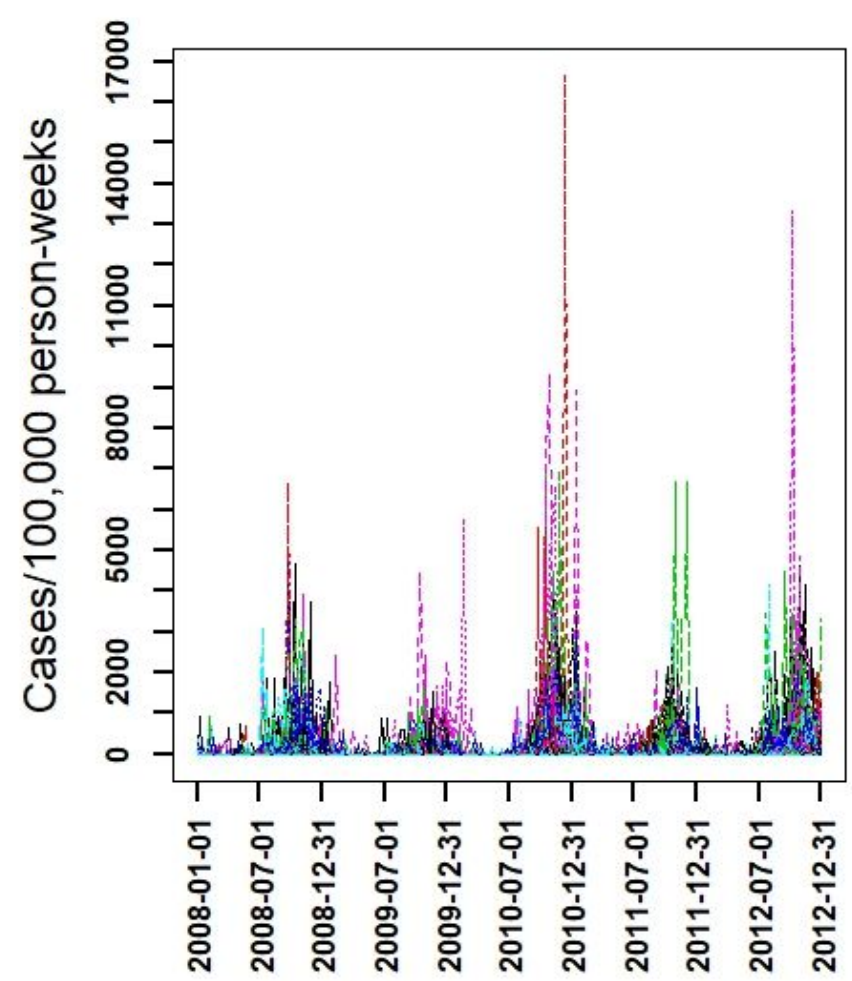

Panel B

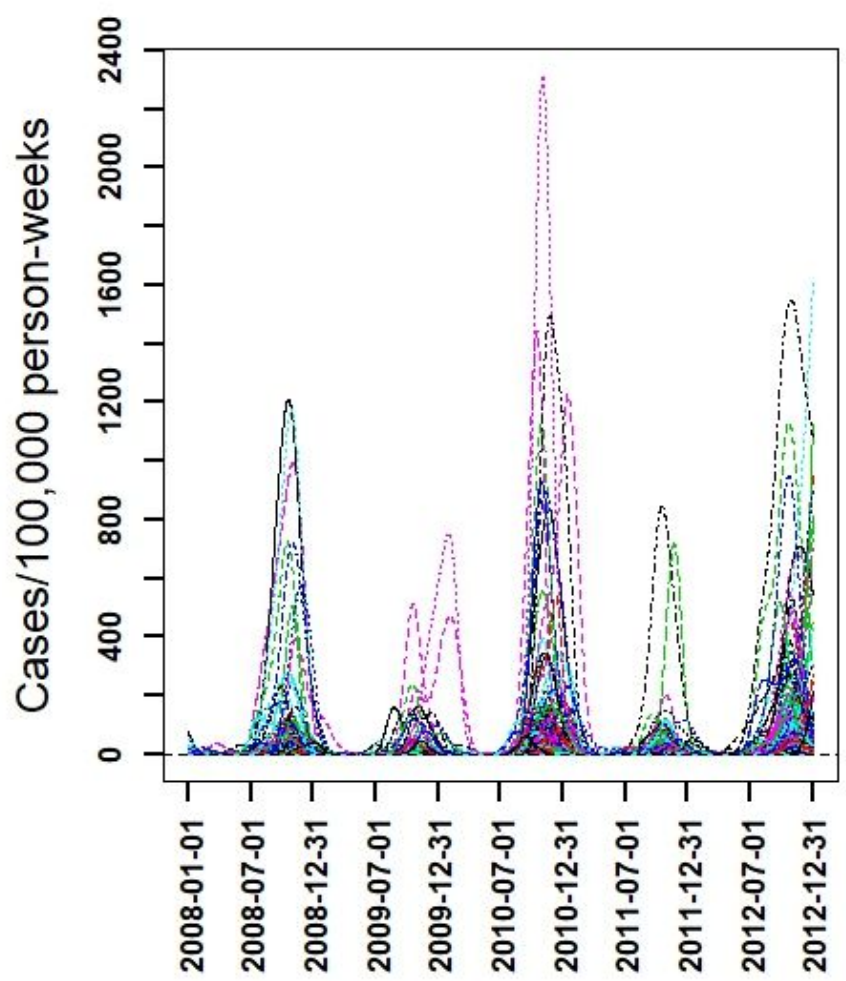

Figure 2

Weekly malaria incidence evolution for each village from January 2008 to December 2012: observed time series (Panel A) and smoothed functions of time series (Panel B) 


\section{Panel A}

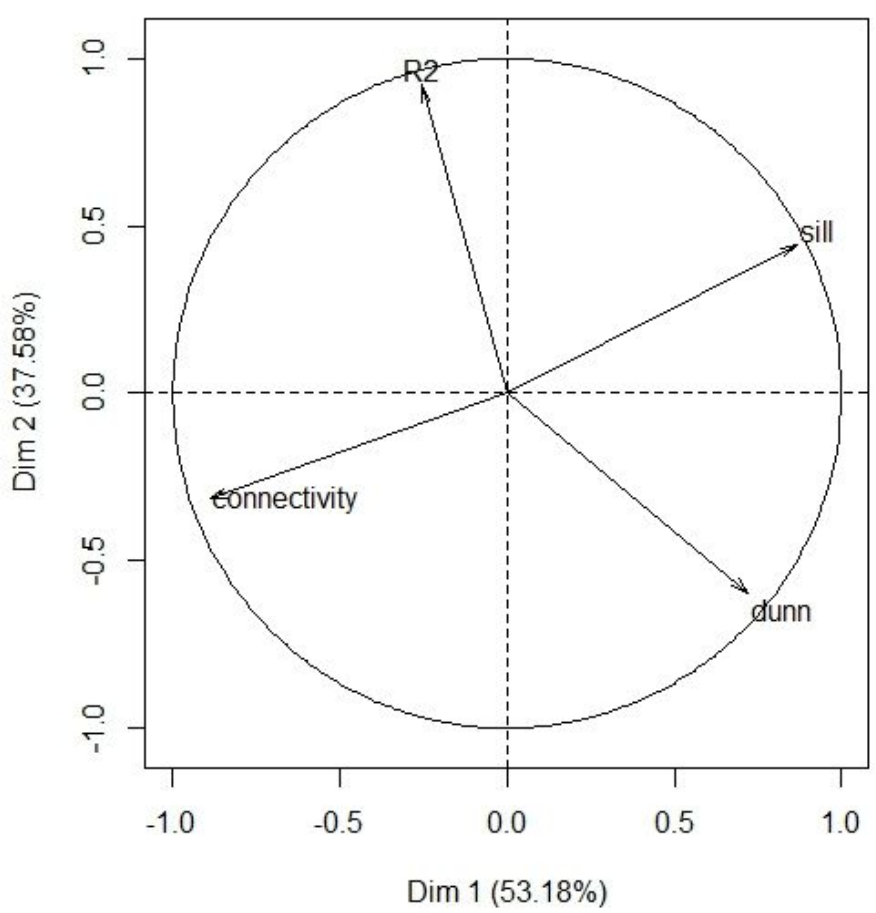

Panel B

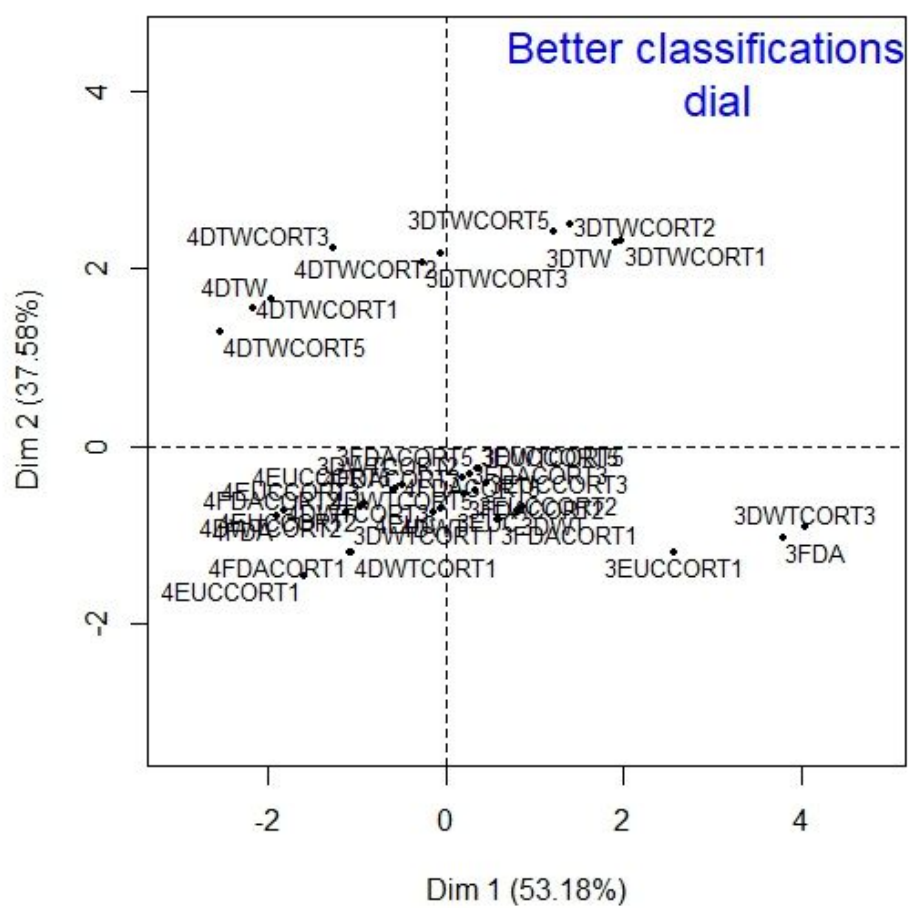

Figure 3

Principal component analysis on validity indices and dissimilarity measures for 3 and 4 number clusters: validity indices map (Variables, Panel A), dissimilarity measures map (Individuals, Panel B)
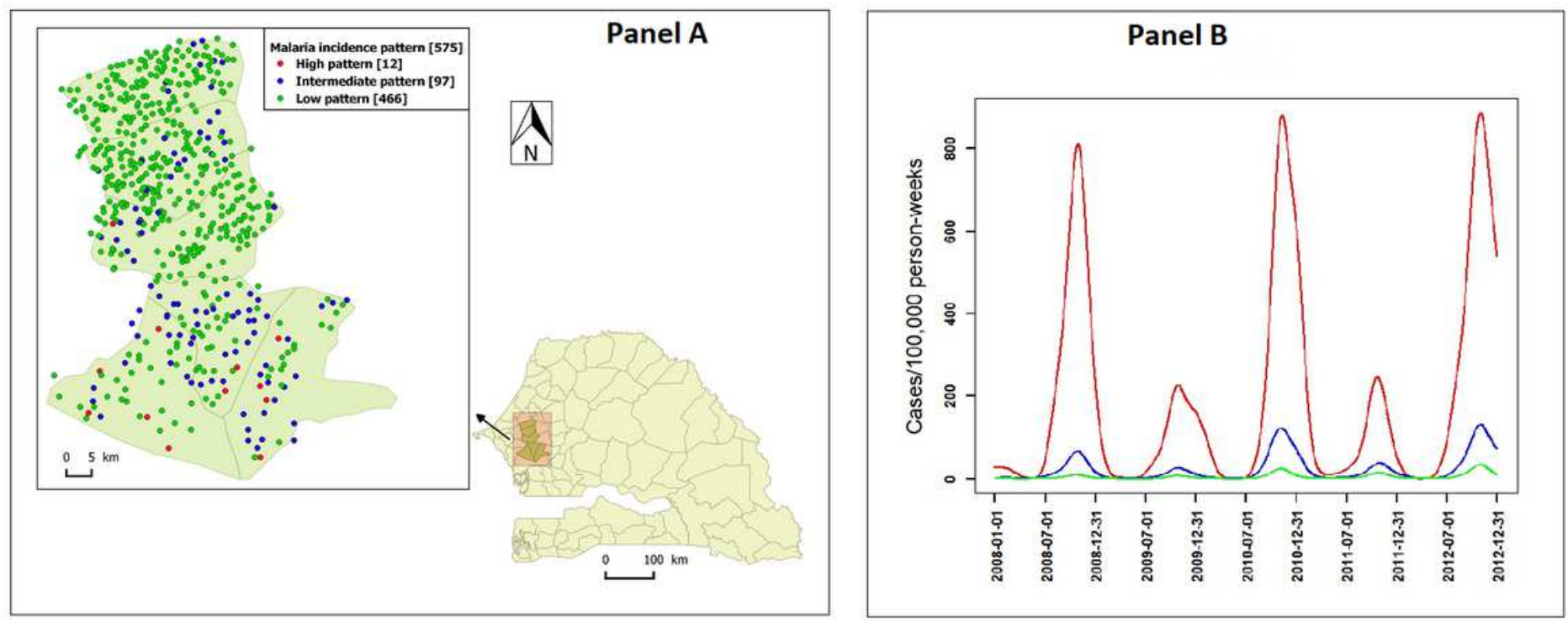

\section{Figure 4}

The spatial distribution of malaria incidence patterns in the area study (Panel A) and smoothed functions for each malaria incidence pattern (Panel B): Senegal map and the location of the study area pointed by 
the arrow, high incidence pattern in red line, intermediate incidence pattern in blue line and low incidence pattern in green line.

\section{Panel A}

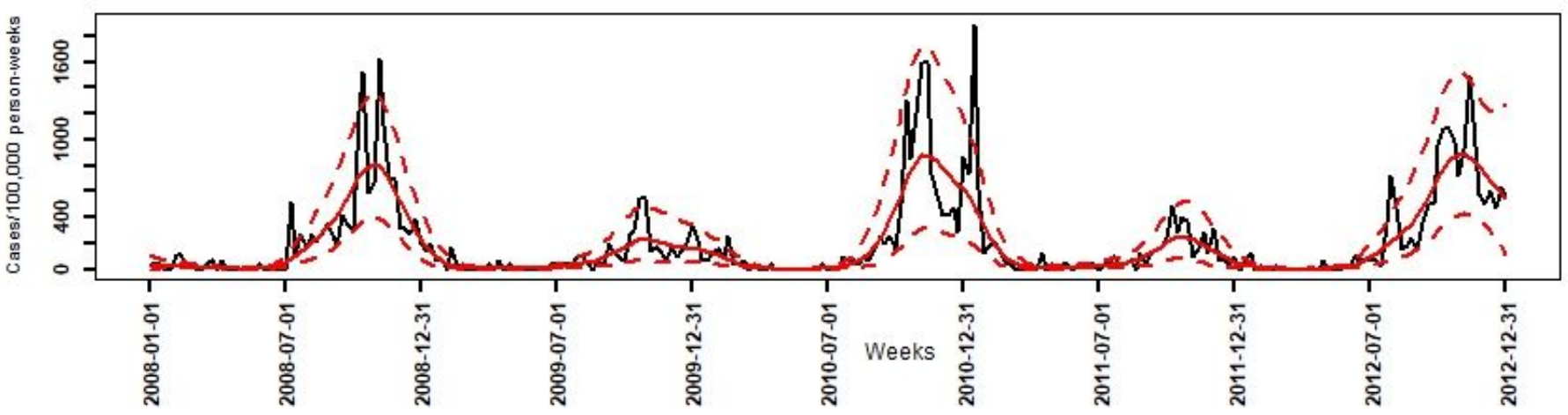

Panel B

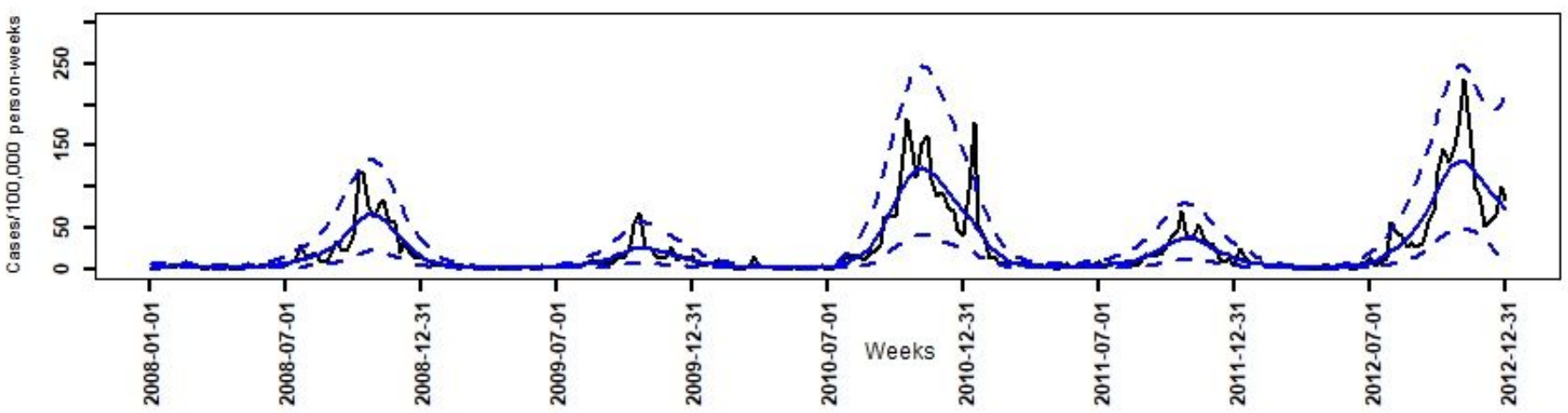

Panel C

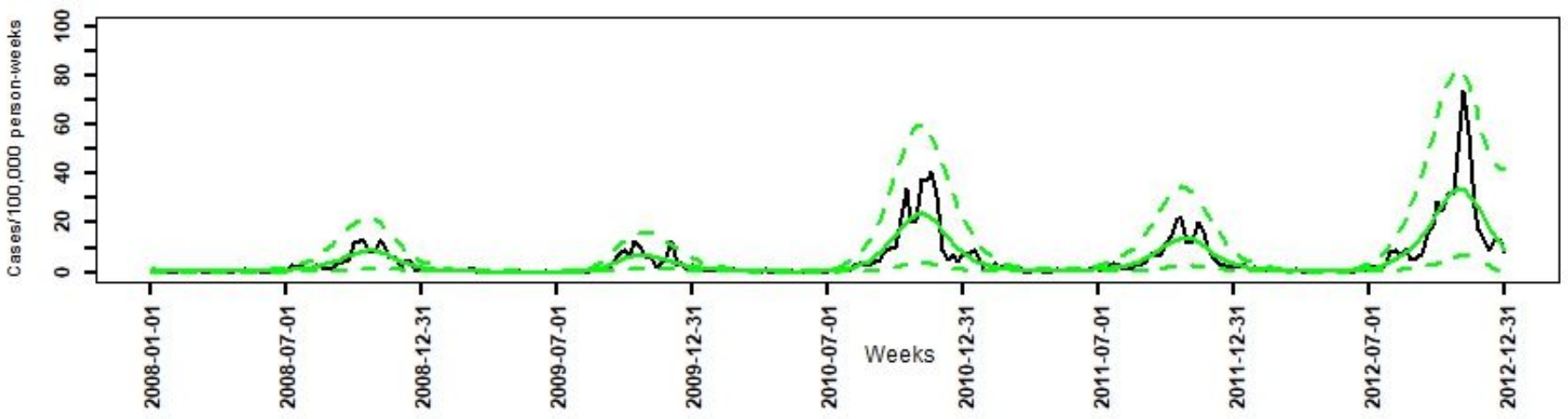

Figure 5

Weekly observed malaria incidence in black solid line, smoothed malaria incidence in color solid line and smooth 95\% point-wise confidence intervals in discontinuous color line : high incidence pattern in red (Panel A), intermediate incidence pattern in blue (Panel B) and low incidence pattern in green (Panel C). 
Panel A

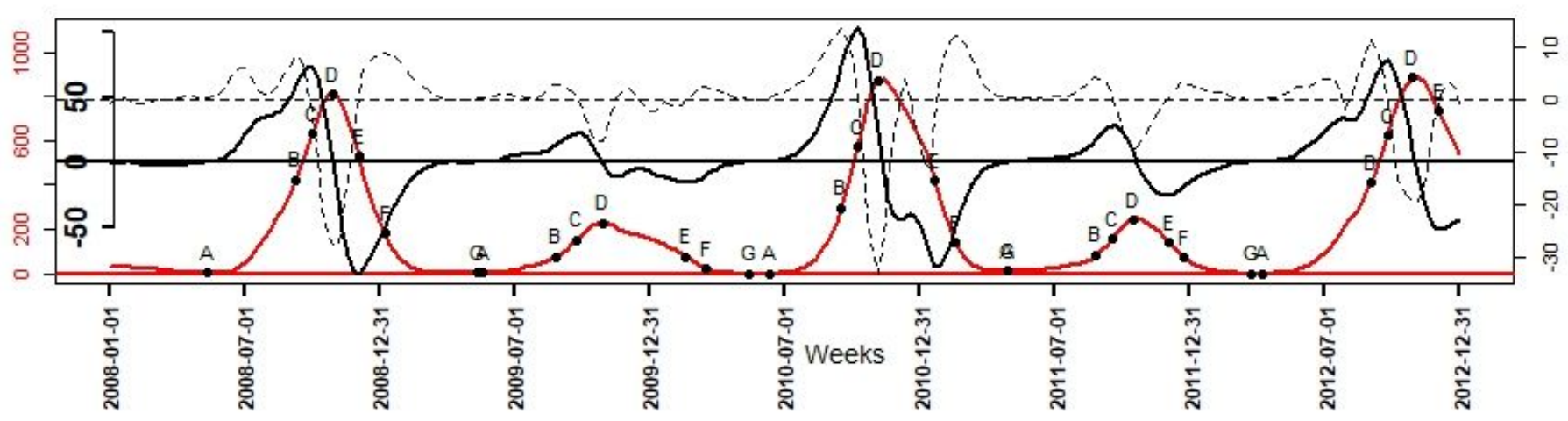

Panel B

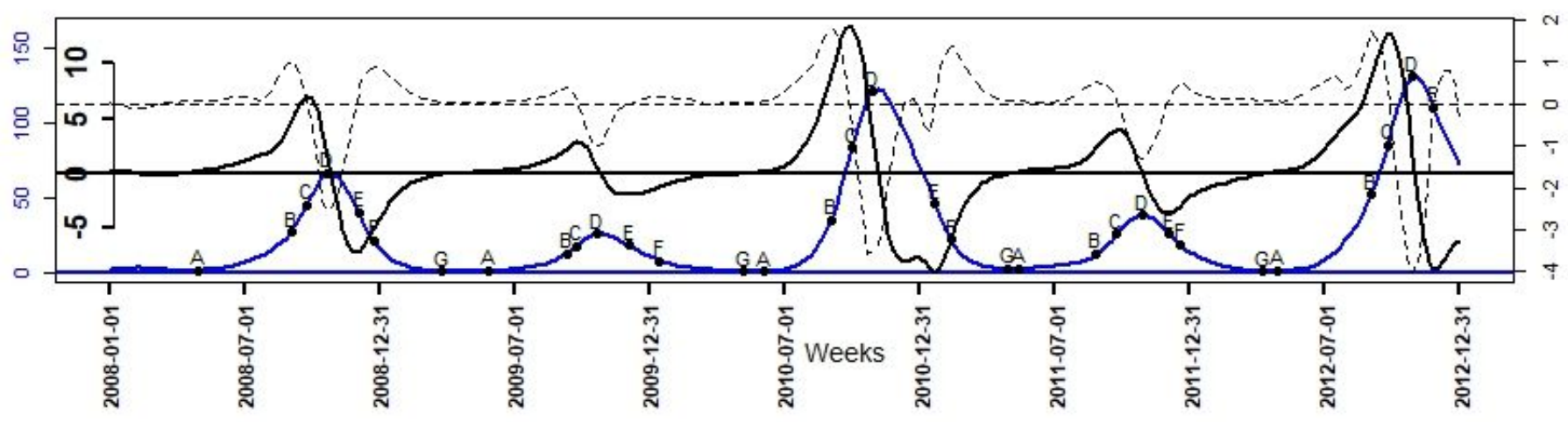

Panel C

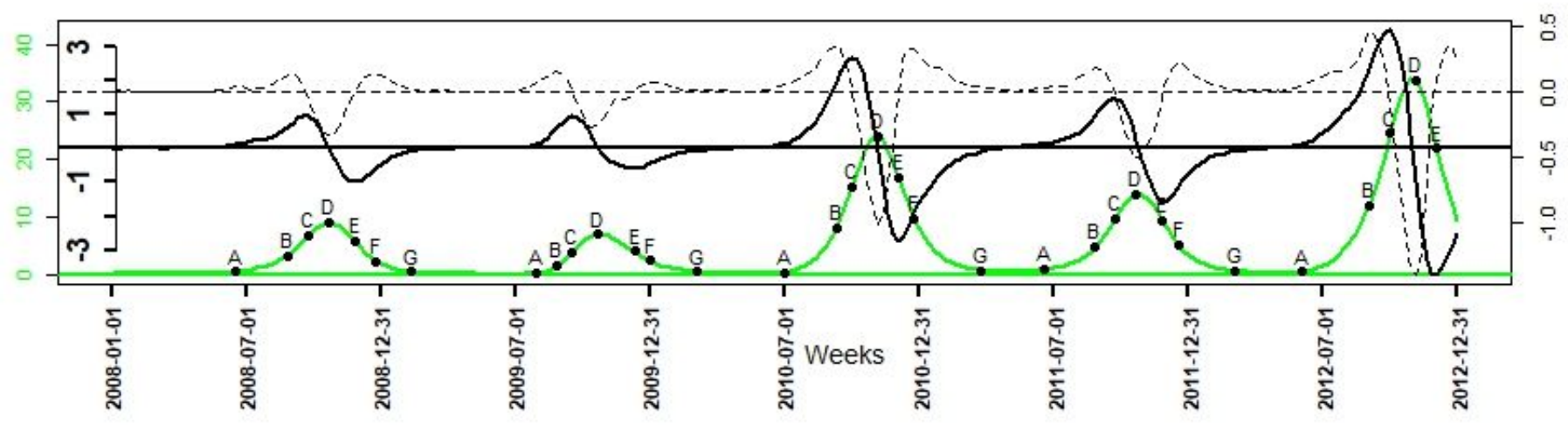

Figure 6

Smoothed incidence in color solid line, their velocity in black bold solid line, their acceleration in black discontinuous line and the epidemiological indicator of their seasonal outbreaks (A: onset, B: near slowdown of growth, C: beginning slowdown of growth, D: Peak, E: beginning acceleration of decline, F: beginning of tail , G: end ): high incidence pattern in red (Panel A), intermediate incidence pattern in blue (Panel B) and low incidence pattern in green (Panel C). 


\section{Panel A}

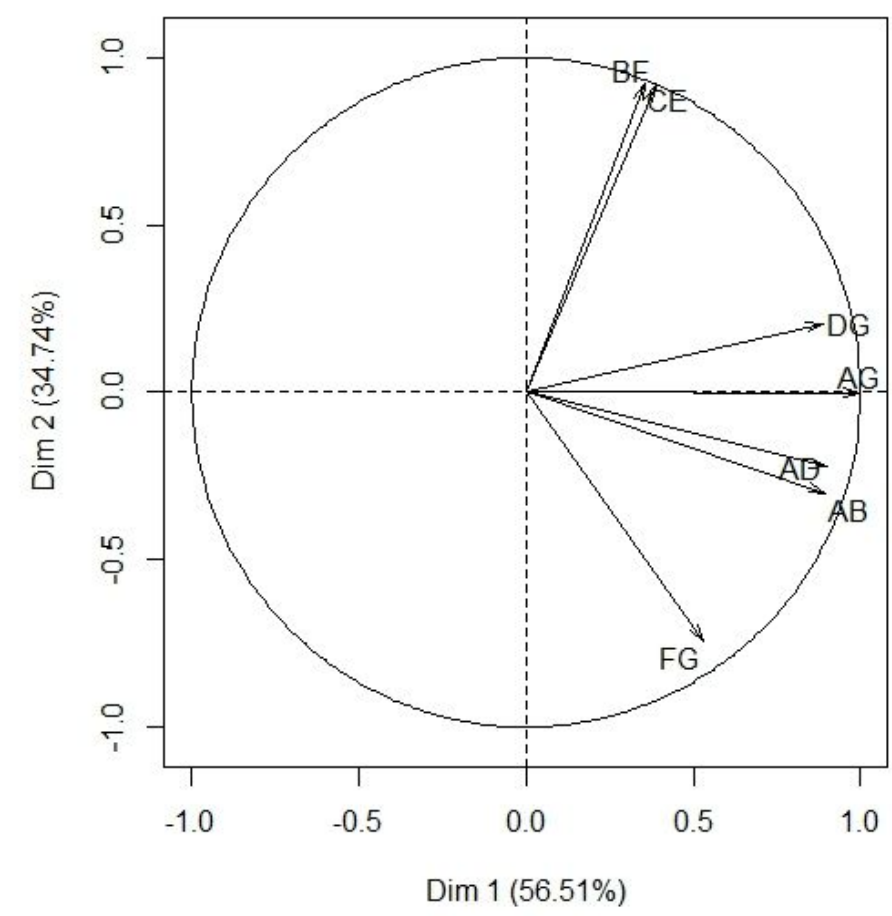

Panel B

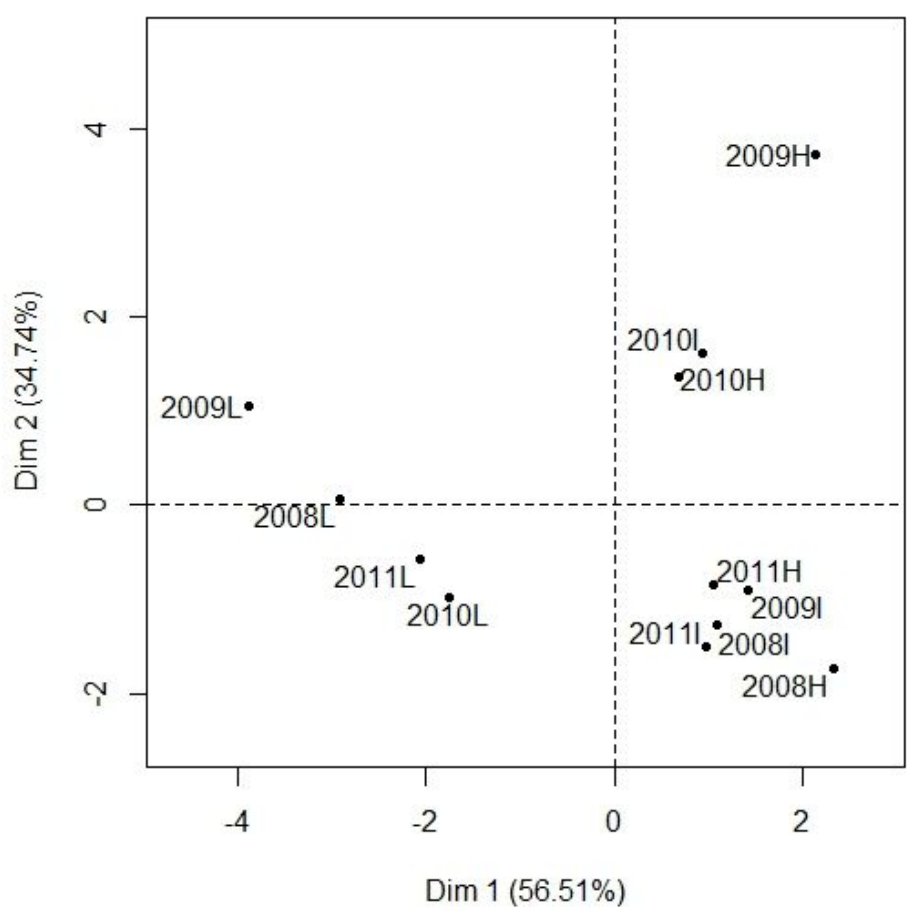

Figure 7

Principal component analysis on duration epidemiological indicator and seasonal outbreaks of the patterns: epidemiological indicator map (Variables, Panel A), seasonal outbreaks of the patterns map (Individuals, Panel B)

\section{Supplementary Files}

This is a list of supplementary files associated with this preprint. Click to download.

- Additionalfile1.docx

- Additionalfile3.jpeg

- Additionalfile2.jpeg

- Additionalfile4.docx 